\title{
Electrochemical Study on Corrosion Inhibition of Iron in acidic medium by Moringaoleifera extract
}

\author{
MESSAOUDA ALLAOUI' ${ }^{1}$ OUMELKHEIR RAHIM ${ }^{1 *}$ and LAKHDARSEKHRI ${ }^{2}$. \\ 'Electrochemical Laboratory, Chemistry Department, Faculty of Mathematics and Matter \\ Sciences, University KasdiMerbah, Ouargla 30000, Algeria. \\ ${ }^{2 *}$ Lab. Dynamic Interactions and Reactivity of Systems, Process Engineering Department, Faculty \\ of Applied Sciences, University KasdiMerbah, Ouargla 30000, Algeria. \\ ${ }^{*}$ Corresponding author E-mail: sekhril@yahoo.fr \\ http://dx.doi.org/10.13005/ojc/330211
}

(Received: March 07, 2017; Accepted: April 04, 2017)

\begin{abstract}
The aim of this work is to investigate corrosion inhibition characteristics of steel $(X 70)$ in chlohydric acid $(1 \mathrm{M})$ in presence of different concentration $\left(1-60 \mathrm{~cm}^{3}\right)$ of Moringaoleifera extract using potentiodynamic polarization studies and impedance measurements. The inhibition efficiency increased with increasing Moringaoleiferaextract concentration; the low concentration $0.25 \% \mathrm{~V} / \mathrm{V}$ was chosen since the inhibition efficiency of the extracts was generally very high. The experimental data showed that the inhibition performance for Tafel and the impedance are $65-70 \%$ and $40-55 \%$ respectively; maximum inhibition could reach about $84-86 \%$ at the concentration of $15 \% \mathrm{~V} / \mathrm{V}$. The results obtained from electrochemical impedance spectroscopy showed that the variation in the impedance parameters, charge transfer resistance and double layer capacitance, with the variation in extract concentration is due to the adsorption of active molecules leading to the formation of a protective layer on the surface of carbon steel. The strong adsorption mechanism between the extract and the mild steel substrate is found to obey Langmuir's, Temkin's and Frumkin's isotherms. All data presented in the present paper suggest that the Moringaoleifera plant has high inhibition efficiency in acid media.
\end{abstract}

Keywords:Moringaoleifera, Polarization methods, Impedance, Corrosion inhibition, Steel(X70), Acid Medium

\section{INTRODUCTION}

Used in a large number of applications mild steel is one of the important metals. Corrosion is the result of the interaction between the metal and environments, leading to its destruction gradually, so corrosion is the deterioration of metal forming chemical attack or interacts with its environment. It is permanent and persistent problem often cannot be eliminated completely. Prevention is more realistic and achievable than the total elimination, and the acid solutions used in industrial processes, acid cleaning, removal of acid deposition, acid pickling and oil wells acidizing, require a corrosion inhibitor to prevent corrosion of metals ${ }^{1,2}$. 
Corrosion inhibitors are substances that, when added in small concentrations to corrosive media decrease or prevent the interaction of the metal with the media. Most effective inhibitors are used to contain a homogenous such as $\mathrm{O}, \mathrm{N}, \mathrm{S}$ and multiple bonds in their molecules by which they stepped on the metal surface. . Some of the physical properties of the group inhibitor have an effect on the absorption, such as ðorbital character, the density of electrons in the atom donor and installation-mail to the molecule functional groups. In spite of the anti-corrosive activity is good, and many synthetic compounds are highly toxic to both humans and the environment ${ }^{3,4}$ these toxic effects associated with the evacuation of these materials have led to develop other environmentally effective and acceptable inhibitors. Therefore, the recent trend is to look for environmentally friendly inhibitors. In most cases, the products are natural non-toxic, biodegradable and bio readily available in many more. Seeds, fruits, leave and flowers are the very important parts of the plant used as corrosion inhibitor ${ }^{5,6}$.

In general, plant extracts are low-cost ecological safe materials for corrosion inhibitors of metals in different media. The term "green inhibitor" or "eco-friendly inhibitor" refers to the substances that are readily available, renewable source, biocompatible in nature and environmentally acceptable. Due to these characteristics, the extracts of some common plants based chemicals and their by-products have been tried as inhibitors for metals under different environments ${ }^{7,8}$. Many extracts of common plants have been found useful, in this regard several investigations and research efforts are carried out for new green inhibitor alternatives ${ }^{9-21}$.

The MoringaOleifera (Moringaceae) is one of these important plants, distributed in many tropical and sub-tropical countries, known with its medical uses of high nutritional value. Different parts of this plant contain a large amount of minerals and considered as suitable source of protein, vitamins and beta-carotene, amino acids and various phenolic compounds.

It also provides rich and rare collection of zeatin, quercetin, beta-sitosterol, caffeoylquinic acid, kaempferol, and a variety of medical uses such as an antioxidant, anti-cancer, anti-inflammatory, antispasmodic, diuretic, Antiulcer, antibacterial and antifungal. Anti properties has shown receiving pain, as well as the ability to heal wounds. In addition, the use of root barks as an analgesic, alexeteric, antihelminthic, and treatment of heart complaints, as well as for eye diseases, inflammation and indigestion $22-27$.

The aim of the present work is to investigate the inhibitive effect of the acid extract of Moringaoleiferaon the hydrochloric acid corrosion of carbon steel by polarization measurements

\section{EXPERIMENTAL}

\section{Extraction of plant materials}

The leaves of Moringaoleiferawere collected in 2016 fromTamanrasset (Province in southern Algeria). The studied plant parts were dried under shade and then ground and stored in a closed container away from light and moisture.

The extract was prepared by soaking 150 $\mathrm{g}$ of the plant powder in a $1 \mathrm{~N} \mathrm{HCl}$ solution for $24 \mathrm{H}$. After filtration, different concentrations were prepared as follows: $0.250 \%, 0.650 \%, 2.50 \%, 3.75 \%, 5.00 \%$, $8.75 \%, 10.00 \%, 12.50 \%$, and $15.00 \%(\mathrm{v} / \mathrm{v})$.

\section{Electrochemical measurements Pratiquas Conditions}

Electrochemical measurements were performed using a personal computer-driven Volta lab 40 model PGZ301 Potentio stat/Galvano state quipped with Volta Master 4 software. A typical three electrodes cell with a working electrode made of carbon steel with an active surface of $1 \mathrm{~cm}^{2}$ was used. The auxiliary electrode was a platinum plate $\left(1 \mathrm{~cm}^{2}\right)$

Table 1: Chemical composition of carbon steel sheet

\begin{tabular}{lcccccccccccccc}
\hline Element & $\mathbf{C}$ & $\mathbf{P}$ & $\mathbf{S}$ & $\mathbf{S i}$ & $\mathbf{M n}$ & $\mathbf{C r}$ & $\mathbf{N i}$ & $\mathbf{C u}$ & $\mathbf{A l}$ & $\mathbf{N b}$ & $\mathbf{V}$ & $\mathrm{Ti}$ & $\mathbf{M o}$ & $\mathbf{F e}$ \\
\hline Value $^{*} 10^{-3}$ & 65 & 2 & 1 & 245 & 1685 & 42 & 26 & 10 & 42 & 67 & 14 & 19 & 5 & Reste \\
\hline
\end{tabular}


and the reference electrode was represented by a saturated calomel electrode (SCE). Potentiodynamic polarization curves were obtained with the scan rate of $0.5 \mathrm{mV} \mathrm{s}^{-1}$, in the potential range of $(-750$ to -200$)$ $\mathrm{mV}$. The immersion time of the plates $\mathrm{X} 70$ in the blank as well as in the presence of different concentrations acid extract of Moringaoleifera was 40 minutes in open circuit at room temperature $23-24^{\circ} \mathrm{C}$.

Electrochemical impedance spectroscopy (EIS) measurements were carried out after 30 minutes immersion time of the carbon steel plates in corrosive media, at the corrosion potential $-476.8 \mathrm{mV}$ $\left(E_{\text {corr }}\right)$, in a frequency range from $100 \mathrm{KHz}$ to $10 \mathrm{mHz}$ by a parturition signal of $10 \mathrm{mV}$ amplitude peak to peak, at room temperature $23-24^{\circ} \mathrm{C}$.

\section{Composition of Specimen sheet}

Working electrodes were cut from a carbon steel sheet. Specimens in the form of discs were used. The chemical of the latter composition of carbon steel sheet is presented in Table 1 (as percentage).

This material (X70) is used widely in petroleum and gas industry. Distilled and deionizer water was used for the preparation of the different solutions and purification of $\mathrm{X} 70$.

\section{RESULTS AND DISCUSSIONS}

To support our development of electrochemical study for corrosion inhibition of iron by lists of numerous chemical compounds that exhibit inhibitive properties.

\section{Open-circuit potential and corrosion potential}

The variation in the open-circuit potential (OCP) and the corrosion potential $\left(\mathrm{E}_{\text {corr }}\right)$ of the carbon steel electrode in $1 \mathrm{M} \mathrm{HCl}$ are reported in Table 2 and plotted in figures 1 and 2 respectivelly.

\section{Potentiodynamic polarization measurements}

The corrosion rate is calculated with the Tafel method according to the 1st Stern equation. The corrosion current density $\left(i_{\text {corr }}\right)$ was determined in the intersect of the anodic and cathodicTafel lines with corrosion potential, using Volta Master 4 software equation
The kinetics of the anodic and cathodic reactions occurring on carbon steel electrodes in 1 $\mathrm{M} \mathrm{HCl}$ solutions with different concentrations of acid extract of Moringaoleifera (0.250-15\%) was studied through the polarization measurements.

The complete potentiodynamic polarization curves are shown in Fig.2. The electrochemical parameters, i.e. corrosion current density $\left(i_{\text {corr }}\right)$, anodic $\left(b_{a}\right)$ and cathodic $\left(b_{c}\right)$ Tafel constants and polarization resistance $\left(R_{p}\right)$ regrouped in Table 2 were collected from Tafel plots and polarization resistance experiments which are carried out separately.

As shown in Fig.2, it can be clearly seen that the $\mathrm{E}_{\text {corr }}$ values shifted to more negative potentials with an increase concentration of acid extract of Moringaoleifera. This effect may be related to the adsorption of the organic compound at the

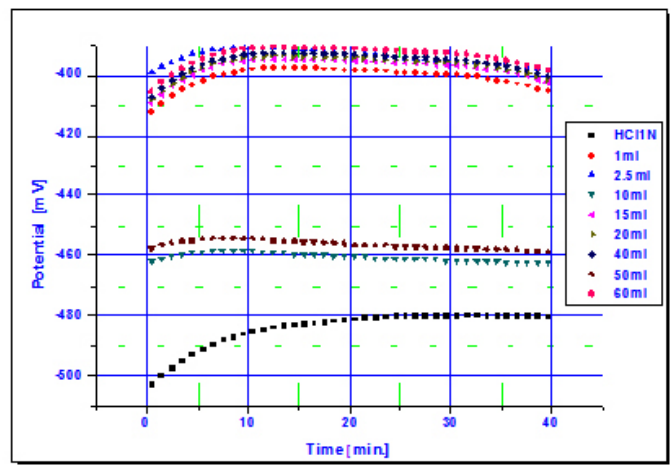

Fig.1: Variation of the open circuit potential with the concentration of acid extract of Moringaoleifera in $1 \mathrm{M} \mathrm{HCl}$ solution

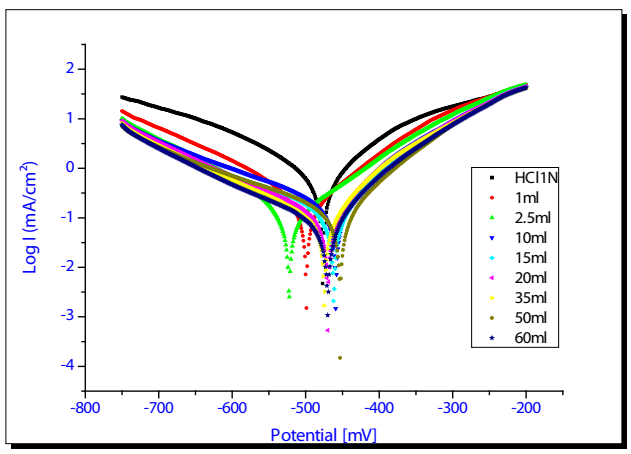

Fig.2: Potentiodynamic polarization curves for carbon steel in $1 \mathrm{M} \mathrm{HCl}$ and solutions containing acid extract of Moringaoleifera 
active sites of the electrode surface, retarding the corrosion reaction. The increase in the concentration of acid extract of Moringaoleifera caused a clear decrease in the cathodic current density, but did not change significantly the cathodicTafel slopes (Table2), indicating that the hydrogen evolution reaction is diminished exclusively by the surface blocking effect.

The $\mathrm{R} \%$, IE\% values were obtained from $\mathrm{i}_{\text {corr }}$ and $\mathrm{R}_{\mathrm{p}}$ data using the equations below:

$$
\begin{aligned}
& R \%=\left(1-\frac{V_{\text {corr }}}{V_{\text {corr }}^{0}}\right) * 100 \\
& I E \%_{\text {icorr }}=\left(1-\frac{i_{\text {corr }}}{i_{\text {corr }}^{0}}\right) * 100
\end{aligned}
$$

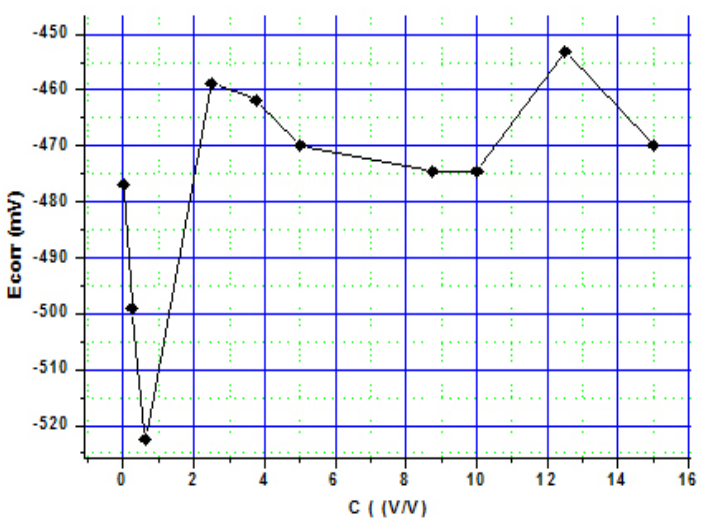

Fig.3: Variation of the corrosion potential with the concentration of acid extract of Moringaoleifera in $1 \mathrm{M} \mathrm{HCl}$ solution

$$
I E \%_{R p}=\left(1-\frac{R_{p}^{0}}{R_{p}}\right) * 100
$$

Where $\mathrm{i}_{\text {corr }}^{0}$ and $\mathrm{R}_{\mathrm{p}}^{0}$ are the corrosion current density and the polarization resistance, respectively, measured in solutions without inhibitor and $\mathrm{i}_{\text {corr }}$ and $R_{p}$ are the same parameters determined in solutions containing inhibitor. The results obtained are given in Table2.

\section{electrochemical impedance spectroscopy measurements}

Electrochemical impedance spectroscopy (EIS) is a well-established and powerful tool in the study of corrosion. Surface properties, electrode kinetics and mechanistic information can be obtained from the impedance diagrams.

The Nyquist plot obtained at the corrosion potential $-476.8 \mathrm{mV}$ of carbon steel in acid medium is displayed in Fig.4, while Table 3 summarize the impedance data extracted from EIS experiments carried out both in the absence and presence of increasing concentrations of acid extract of Moringaoleifera.

The impedance parameters derived from EIS measurements $R_{\mathrm{s}}, R_{\mathrm{ct}}, C_{\mathrm{dl}}$ were determined using Volta Master 4 software with an error of $\pm 1 \%$, and are listed in Table 3.

In acid extract of Moringaoleifera -free solution, a depressed charge transfer semicircle is observed at high frequency, which is attributed to the

\begin{tabular}{|c|c|c|c|c|c|c|c|c|c|c|}
\hline $\begin{array}{l}\mathrm{HCl} \\
1 \mathrm{M}\end{array}$ & $\begin{array}{r}C \% \\
(V / V)\end{array}$ & $\begin{array}{r}R p \\
\left(o h m . \mathrm{cm}^{2}\right)\end{array}$ & $\begin{array}{l}\text { IE\% } \\
\text { (Rp) }\end{array}$ & $\begin{array}{c}E_{\text {corr }} \\
(\mathrm{mV})\end{array}$ & $\begin{array}{r}i_{\text {corr }} \\
(\mathrm{mA} / \mathrm{cm})\end{array}$ & $\begin{array}{l}\text { IE\% } \\
\left(\mathbf{i}_{\text {corr }}\right)\end{array}$ & $\begin{array}{r}V_{\text {corr }} \\
(\mathrm{mm} / \mathrm{an})\end{array}$ & $\mathbf{R} \%$ & $\begin{array}{r}\beta a \\
(m V)\end{array}$ & $(\mathrm{mV})^{\beta_{\mathrm{c}}}$ \\
\hline Oml & 0 & 37.07 & & -476.8 & 0.4549 & & 5.320 & & 81.2 & -102.2 \\
\hline $1 \mathrm{ml}$ & 0.25 & 110.43 & 66.431 & -499.2 & 0.1327 & 70.829 & 1.552 & 70.827 & 83.9 & -83.4 \\
\hline $2.5 \mathrm{ml}$ & 0.625 & 167.12 & 77.818 & -522.4 & 0.0892 & 80.391 & 1.042 & 80.414 & 99.5 & -83.1 \\
\hline $10 \mathrm{ml}$ & 2.5 & 125.41 & 70.441 & -458.8 & 0.1268 & 72.126 & 1.482 & 72.143 & 66.8 & -135.8 \\
\hline $15 \mathrm{ml}$ & 3.75 & 175.88 & 78.923 & -461.7 & 0.0859 & 81.117 & 1.005 & 81.109 & 64.5 & -116.1 \\
\hline $20 \mathrm{ml}$ & 5 & 185.52 & 80.018 & -469.9 & 0.0840 & 81.534 & 0.9826 & 81.530 & 64.0 & -131.5 \\
\hline $40 \mathrm{ml}$ & 10 & 198.99 & 81.371 & -474.6 & 0.07457 & 83.607 & 0.8722 & 83.605 & 66.6 & -128.6 \\
\hline $50 \mathrm{ml}$ & 12.5 & 180.11 & 79.418 & -453.0 & 0.09226 & 79.719 & 1.079 & 79.718 & 70.6 & -137.3 \\
\hline $60 \mathrm{ml}$ & 15 & 280.34 & 86.777 & -469.9 & 0.05996 & 86.819 & 0.7013 & 86.818 & 65.2 & -134 \\
\hline
\end{tabular}

Table 2: Electrochemical parameters for carbon steel in $1 \mathrm{M} \mathrm{HCl}$ solutions containing acid extract of Moringaoleifera 
time constant of the charge transfer and double-layer capacitance. The intersection of this semicircle with the real axis at high frequencies furnished a value of 1.678-2.265 blank $\Omega \mathrm{cm}^{2}$ for the ohmic resistance $\left(R_{s}\right)$ of the solution enclosed between the working electrode and the tip of the salt bridge containing the reference electrode. At low frequencies, a charge transfer resistance $\left(\mathrm{R}_{\mathrm{ct}}\right)$ of 268.60-42.42 blank $\Omega$ $\mathrm{cm}^{2}$ was found from the difference in impedances at lower and higher frequencies. The double-layer capacitance $\mathrm{A} \mathrm{C}_{\mathrm{dl}}$ value of 37.43-118.5 $\mu \mathrm{F} \mathrm{cm}^{-2}$ was found for the carbon steel electrode in the blank $1 \mathrm{M} \mathrm{HCl}$ solution and $f_{\max }$ was calculated from the equation below:

$$
f_{\max }=f_{-i z_{\max }}=\frac{1}{2 \pi C_{d l} R_{C t}}
$$

Where $f_{\max }$ is the frequency value at which the imaginary component of the impedance is maximal.

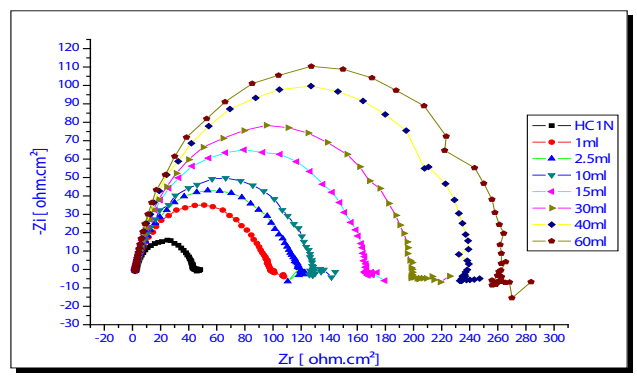

Fig. 4: Nyquist plots for carbon steel in $1 \mathrm{M} \mathrm{HCI}$ and solutions containing acid extract of Moringaoleifera
The values observed for $R_{s}, R_{c t}$ and $C_{d l}$ for carbon steel in corrosion inhibitor-free solutions are in agreement with the values reported recently ${ }^{6,7}$. The Nyquist plots shown in Fig. 4 for carbon steel electrodes immersed in $1 \mathrm{M} \mathrm{HCl}$ solutions containing $0.25-15 \%(\mathrm{v} / \mathrm{v})$ acid extract depict a behavior analogous to that observed in solutions without the inhibitor, indicating that mainly a charge transfer process controls the corrosion of carbon steel.

Deviations from a perfect circular shape indicate frequency dispersion of interfacial impedance arising from a lack of homogeneity of the electrode surface due to roughness or interfacial phenomena'. However, it is worth noting that the impedances increase in the presence of acid extract of Moringaoleifera, but the electrochemical reactions responsible for corrosion do not change. These results support those obtained from the Tafel experiments for lower acid extract of Moringaoleifera concentration and confirm the inhibitor adsorption onto the carbon steel surface. As can be seen in Table 3, slightly higher $R_{s}$ values were obtained in the presence of the corrosion inhibitor. This was to be expected because, in general, organic inhibitor reduces the dielectric constant of aqueous solutions, increasing their resistance. More important, however, are the observations related to $\mathrm{C}_{\mathrm{dl}}$ and $\mathrm{R}_{\mathrm{ct}}$.

As it is obvious from the EIS results, the acid extract of Moringaoleifera decreases the doublelayer capacitance and increases the charge transfer resistance; as consequence a larger diameter of the semicircle is observed in Nyquist plots. The decrease

Table 3: Impedance data and surface coverage for carbon steel in $1 \mathrm{M} \mathrm{HCl}$ and solutions containing acid extract of Moringaoleifera

\begin{tabular}{|c|c|c|c|c|c|c|c|c|}
\hline $\begin{array}{l}\mathrm{HCl} \\
1 \mathrm{M}\end{array}$ & $\begin{array}{c}C \% \\
(V / V)\end{array}$ & $\begin{array}{c}\mathbf{R}_{\mathrm{s}} \\
(\mathrm{ohm} . \\
\mathrm{cm}^{2} \text { ) }\end{array}$ & $\begin{array}{c}\mathbf{R}_{\mathrm{ct}} \\
\text { (ohm. } \\
\text { cm }^{2} \text { ) }\end{array}$ & $\begin{array}{c}\text { IE }_{\text {Rct }} \\
\%\end{array}$ & $\begin{array}{c}\mathrm{C}_{\mathrm{dl}} \\
\left(\mu \mathrm{F} / \mathrm{cm}^{2}\right)\end{array}$ & $\begin{array}{c}\mathrm{IE}_{\mathrm{Cdl}} \\
\%\end{array}$ & $\begin{array}{c}\mathbf{f}_{\max } \\
(\mathbf{H z})\end{array}$ & $\begin{array}{c}\text { Depletion } \\
\text { angle }\left({ }^{\circ}\right)\end{array}$ \\
\hline Oml & 0 & 2.263 & 42.42 & & 118.5 & & 31.678 & -9.32 \\
\hline $1 \mathrm{ml}$ & 0.25 & 2.041 & 94.75 & 55.230 & 67.18 & 43.308 & 25.016 & -8.77 \\
\hline $2.5 \mathrm{ml}$ & 0.625 & 1.911 & 114.6 & 62.984 & 55.51 & 53.156 & 25.031 & -8.35 \\
\hline $10 \mathrm{ml}$ & 2.5 & 2.032 & 126.3 & 66.413 & 50.37 & 57.494 & 25.030 & -7.04 \\
\hline $15 \mathrm{ml}$ & 3.75 & 1.858 & 164.6 & 74.228 & 38.65 & 67.384 & 25.030 & -6.43 \\
\hline $30 \mathrm{ml}$ & 5 & 1.811 & 196.6 & 78.423 & 40.47 & 65.848 & 20.014 & -6.48 \\
\hline $40 \mathrm{ml}$ & 8.75 & 2.065 & 239.7 & 82.303 & 41.96 & 64.591 & 15.832 & -5.52 \\
\hline $60 \mathrm{ml}$ & 15 & 1.678 & 268.6 & 84.207 & 37.43 & 68.414 & 15.839 & -5.46 \\
\hline
\end{tabular}


in $\mathrm{C}_{\mathrm{dl}}$ can be interpreted as due to the adsorption, in this case of acid extract of Moringaoleifera on the electrode surface. The double layer formed at the electrode-solution interface is considered as an electric capacitor, whose capacitance decreases due to the displacement of water molecules and other ions originally adsorbed on the electrode by the acid extract of Moringaoleifera molecules, forming a protective film. The thickness of the film formed increases with increasing concentrations of the inhibitor, since more acid extract of Moringaoleifera adsorbs on the surface, resulting in lower $\mathrm{C}_{\mathrm{dl}}$ values. The $R_{c t}$ values were used to calculate the IE\%, according to the equation:

$$
\begin{aligned}
& I E_{R C t} \%=\left(1-\frac{R_{C t}^{\circ}}{R_{C T}}\right) * 100 \\
& I E_{C d l} \%=\left(1-\frac{C_{d l}}{C_{C d l}^{0}}\right) * 100
\end{aligned}
$$

Where $\mathrm{R}_{\mathrm{ct}}^{0}, \mathrm{C}_{\mathrm{dl}}{ }^{0}$ and $\mathrm{R}_{\mathrm{ct}}, \mathrm{C}_{\mathrm{dl}}$ are the charge transfer resistance and double-layer capacitance in the blank solution and in the presence of organic corrosion inhibitor respectively.

The results obtained are shown in Table 3. It can be clearly seen that the $R_{c t}$ value increases with the inhibitor concentration, leading to an increase in the corrosion inhibition efficiency. The IE\% values calculated from the EIS values are in complete agreement with those obtained from the Tafel polarization resistance experiments. The slight discrepancy in the IE\% values obtained from different techniques can be interpreted as the result of different measurement times .Therefore, these results suggest, once again, the formation of an insoluble inhibitor film due to the adsorption of natural's molecules of extract acid onto the carbon steel surface.

Figs. 4 and 5, respectively, shows the Nyquist and Bode plots for carbon steel in X70 without and with various concentrations of acid extract of Moringaoleifera; it appears that the impedance response of carbon steel in X70 shows a significant change after addition of acid extract of Moringaoleifera. (Fig.4). this indicates that the carbon steel impedance increases with increasing the inhibitor concentration and, consequently, the inhibition efficiency increases. As shown in Fig.4, it can be seen that Nyquist curves are consisted in one capacitive loop, corresponding to one phase angle maximum in Bode diagram(one time-constant in Bode-phase representation) or two capacitive semicircles (two well-defined time-constants in Bode-phase format). Fig. 5 represents Bode plots in $\mathrm{HCl} 1 \mathrm{M}$, Bode plots of phase angle vs. frequency for carbon steel in $1 \mathrm{M} \mathrm{HCl}$ in presence of different concentrations of the plant extract and Bode plots of $\log Z$ vs. frequency for carbon steel in $1 \mathrm{M} \mathrm{HCl}$ presence of different concentrations of the plant extract.
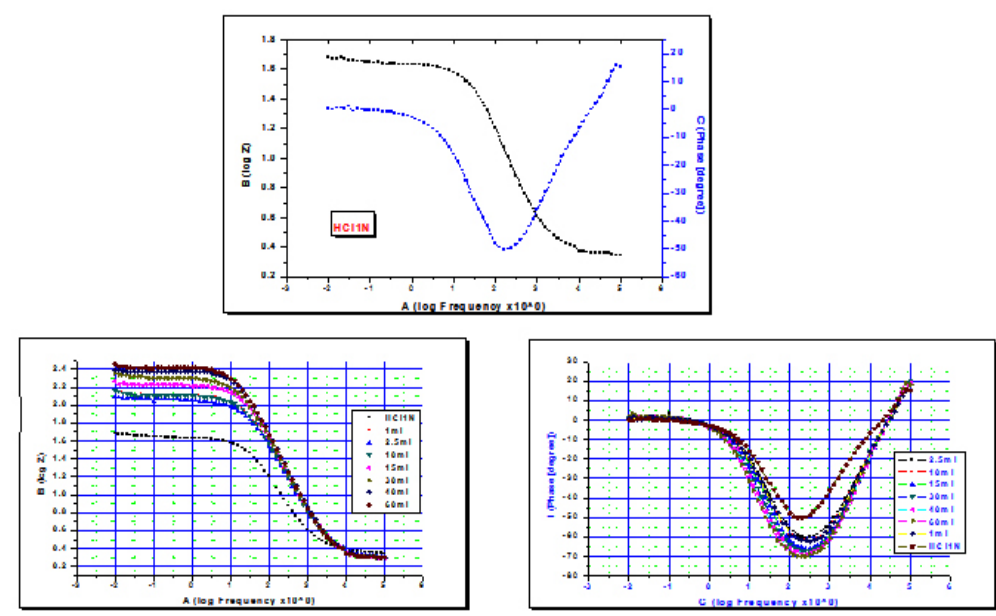

Fig.5: Bode plots for carbon steel corroded in (X70) without and with various concentrations of acid extract of Moringaoleifera after immersion time of $\mathbf{3 0}$ minutes, at room temperature $23-24^{\circ} \mathrm{C}$. 
The fraction of the surface covered by adsorbed molecules was determined according to the ratio reported recently by K. Mansouriet al., ${ }^{28}$.

$$
\begin{aligned}
& \theta=\frac{E \%}{100} \\
& \theta_{\text {icorr }}=\left(1-\frac{i_{\text {corr }}}{i_{\text {corr }}^{\circ}}\right) \text { Or } \quad \theta_{R p}=\left(1-\frac{R_{P}^{0}}{R_{P}}\right) \\
& \theta_{c d l}=\left(1-\frac{C d l^{0}}{C d l}\right) \text { Or } \quad \theta_{R c t}=\left(1-\frac{R_{C t}^{0}}{R_{C t}}\right)
\end{aligned}
$$

Where $\mathrm{i}_{\text {corr }}, \mathrm{R}_{\mathrm{p}}, \mathrm{R}_{\mathrm{ct}}, \mathrm{C}_{\mathrm{dl}}$ are the parameters in presence of inhibitor.

$\mathrm{i}^{0}{ }_{\text {corr }}, \mathrm{R}_{\mathrm{p}}{ }^{0}, \mathrm{R}_{\mathrm{ct}}{ }^{0}, \mathrm{C}_{\mathrm{dl}}{ }^{0}$ are the parameters in absence of the inhibitor.

\section{Adsorption isotherms}

In order to evaluate the adsorption process of acid extract of Moringaoleifera on the carbon steel

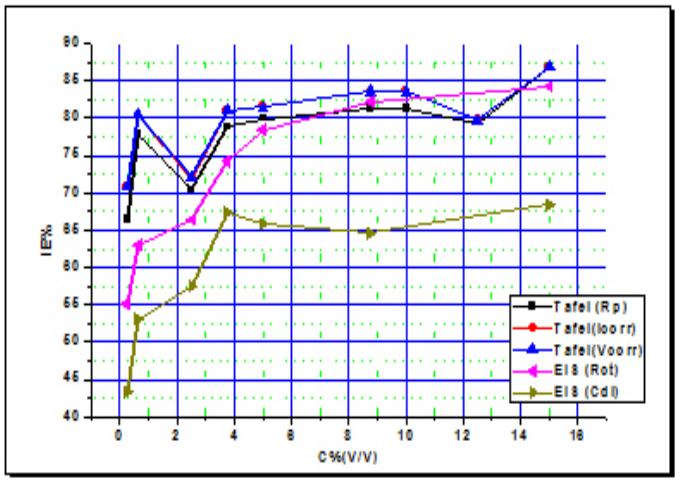

Fig.6: Variation of the inhibition efficiency with the concentration acid extracts of Moringaoleifera in $\mathrm{HCl} 1 \mathrm{M}$ solution surface, Langmuir, Temkin and Frumkin adsorption isotherms were obtained according to the following equations ${ }^{23-25}$.

Langmuir: $\theta /(1-\theta)=\mathrm{KC}$

Temkin: $\log (\theta / C)=\log \mathrm{K}-\mathrm{g} \theta$

Frumkin: $(\theta /(1-\theta)) \mathrm{e}^{(-\mathrm{g} \theta)}=\mathrm{K} \cdot \mathrm{C}$

Or its linear form: $\log (\theta /(1-\theta) C)=$ Logk + g. $\theta$

Where is the surface coverage, $\mathrm{K}$ the adsorption-desorption equilibrium constant, C the inhibitor concentration and $g$ the adsorbate interaction parameter? Considering that the double-layer capacitance is proportional to express the adsorption quantitatively, different adsorption isotherms may be applied. These isotherms characterize the metal/inhibitor/environment system and fit the degree of surface coverage (è) values.

Fig.7.Isotherms for the adsorption of acid extract of Moringaoleifera on the surface of carbon steel in $1 \mathrm{M} \mathrm{HCl}$ with the method polarization measurements

In our study with the method polarization measurements, the best fit was found to obey Langmuir adsorption isotherm which may be expressed by Equations (11) also showed a good correlation with experimental data

$$
\text { Langmuir } \mathrm{I}_{\text {corro }}: c / \theta=0.255 \text { - 1017706.C }
$$
$: \mathrm{R}^{2}=0.99609$

$$
\text { Langmuir } \mathrm{R}_{\mathrm{p}}: \mathrm{c} / \theta=0.31161-1.18187 \text {. }
$$

Table 5: Isotherms for the adsorption of acid extract of Moringaoleiferaon the surface of carbon steel in $1 \mathrm{M} \mathrm{HCl}$

\begin{tabular}{lllll}
\hline \multirow{2}{*}{ isotherme } & \multicolumn{2}{l}{ Equation linear } & R2 & g Or a \\
\hline \multirow{2}{*}{ Langmuir } & Rct & $(\mathrm{C} / \Theta)=1.163 \mathrm{C}+0.479$ & 0.996 & -1.163 \\
& Cdl & $(\mathrm{C} / \Theta=1.453 \mathrm{C}+0.373$ & 0.996 & -1.453 \\
\multirow{2}{*}{ Temkin } & Rct & $\log (\Theta / C)=-5.077 \Theta+3.080$ & 0.926 & 5.077 \\
& Cdl & $\log (\Theta / C)=-5.642 \Theta+2.734$ & 0.834 & 5.642 \\
\multirow{2}{*}{ Frumkin } & Rct & $\log (\Theta \Theta /(1-\Theta) C)=-3.515 \Theta+2.537$ & 0.842 & -3.515 \\
& Cdl & $\log (\Theta /(1-\Theta) C)=-4.623 \Theta+2.530$ & 0.765 & -4.623 \\
\hline
\end{tabular}



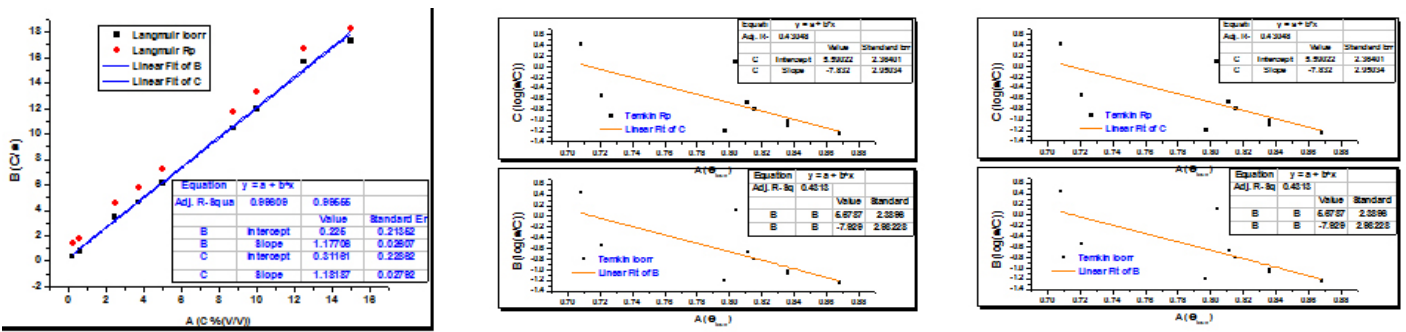

Fig.7: Isotherms for the adsorption of acid extract of Moringaoleifera on the surface of carbon steel in $1 \mathrm{M} \mathrm{HCl}$ with the method polarization measurements
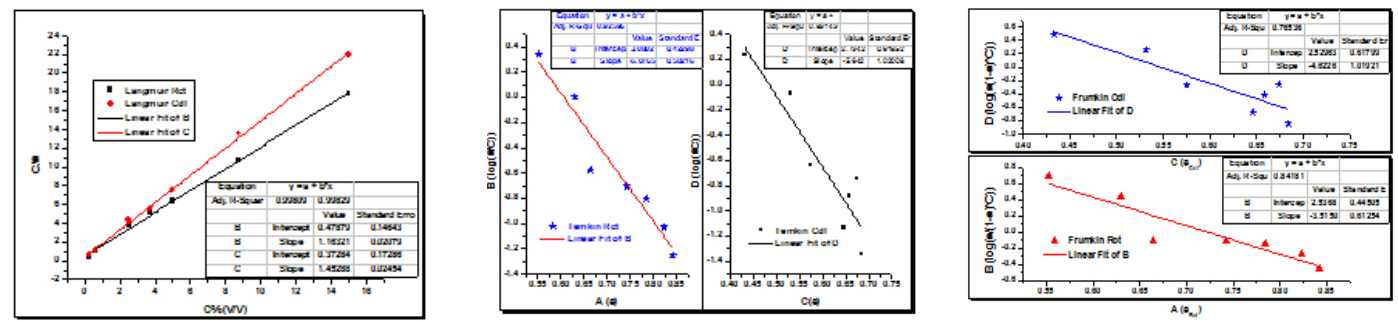

Fig.8: Isotherms for the adsorption of acid extract of Moringaoleifera on the surface of carbon steel in $1 \mathrm{M} \mathrm{HCl}$ with the method EIS.

$C ; R^{2}=0.99555$

$\log (/(1-) C)=-3.515+2.537$

The values of the constant $K$ and the standard free energy of Adsorption by different isotherms for natural's molecules of acid extract of Moringaoleifera are shown in the table 5.

Plot of $\mathrm{C} /=\mathrm{f}(\mathrm{C})$ is displayed in Fig.8. It observed that straight lines are obtained. For the inhibitor, the slope of the straight line is equal to unity while the straight line obtained in case of acid extract of Moringaoleifera has a slope 1.17706 and $1.1887>1$. As a consequence, acid extract of Moringaoleifera adsorption obey the Langmuir isotherm without interaction between the adsorbed molecules. In case of acid extract of Moringaoleiferamolecules, deviation of the slope from unity can be explained in terms of repulsion or attraction of the adsorbed molecules adjacent to each other, a fact which was ignored during the derivation of Langmuir isotherm. The interaction between of acid extract of Moringaoleifera molecules can be ascribed to the steric hindrance of natural compounds.

Adsorption of acid extract of Moringaoleiferamolecules was found to obey Frumkin's model which is given by linear equation:

$\log (/(1-) C)=-4.623+2.530$

On the light of these results, the characteristic parameters of adsorption of acid extract of Moringaoleifera were found to obey Temkin's isotherm: $\mathbf{g}=5.077$ and 5.642, $\log \mathrm{K}=$ -3.080 and -2.734 , The negative value of $\mathrm{g}$ indicates the presence of repulsive forces between the adsorbed species of adsorbed molecules.

\section{CONCLUSION}

Moringaoleiferaplant has been successfully studied as a corrosion inhibitor for carbon steel in $1 \mathrm{~N} \mathrm{HCl}$. Exploration of Electrochemical studies prove that this plant is excellent corrosion inhibitor for carbon steel under acidic conditions. Inhibition efficiency increases with increasing inhibitor concentration and the maximum inhibition efficiency was more than $80 \%$ at the inhibitor concentration 15 $\% \mathrm{v} / \mathrm{v}$ whereas economical inhibition was achieved in $0.25 \% \mathrm{v} / \mathrm{v}$ and maximum inhibition efficiency was about $80 \%$. Very well agreement between the inhibitions efficiencies calculated using polarization techniques was obtained. 
Corrosion inhibition is mainly being due to the adsorption of the plant constituents on the carbon steel surface. Polarization studies indicated that the extract is mixed type inhibiting both cathodic as well as anodic reactions. Acid extract of Moringaoleifera acidic acts as adsorption inhibitor on carbon steel surface; adsorption is spontaneous; Langmuir, Temkin and Frumkin isotherms provides it a good description.

\section{ACKNOWLEDGMENT}

The authors wish to express their sincere thanks to Algerian Ministry of Higher Education and Scientific Research (MHESR) for their support and providing the necessary facilities to carry out this research.

\section{REFERENCES}

1. Idenyi, N.E.,Nwofe, P.A. and. Idu,H.K., Influence of MoringaOleifera and PsiduimQuajava Leaves Extract on the Corrosion Susceptibility of Mild Steel in an Alkaline Medium, Journal of Applied Sciences Research, 2015, 11(22):158-163.

2. D. Benmessaoud Left, D.,Zertoubi, M.,Irhzo, A.,Azzi, M., oils and extracts plants as corrosion inhibitors for different metals and alloys in hydrochloric acid medium, J. Mater. Environ. Sci., 2013, 4 (6): 855-866.

3. Ambrish Singh, Eno E. Ebenso, and Quraishi,M. A., Corrosion Inhibition of Carbon Steel in $\mathrm{HCl}$ Solution by Some Plant Extracts, International Journal of Corrosion.,2012, 13.

4. Ramya, K., Muralimohan, N., Study on Corrosion Inhibitor in Mild Steel by Various Habitual Plant Extract - Review, Int.J. Chemical Concepts. 2016,2(2):70-75.

5. ArockiaSelvi, J.,Kamaraj, P.,Arthanareeswari, M., and AminuDabo, A., Corrosion Inhibition of Mild Steel in Acid Medium by MoringaOleifera and LettuciaEdibelia Extracts, International Journal of Advanced Chemical Science and Applications (IJACSA), 2015: 3, 4-16.

6. Ameena Mohsen Al-Bonayan, Corrosion Inhibition of Carbon Steel in Hydrochloric Acid Solution by Senna-Italica Extract, IJRRAS, February 2015: 22 (2).

7. Idu,H.K.,Nwofe,P.A.,Kalu, P.N. and, Idenyi,N.E., Moringaoleifera and Psidiumguajava Leaves Extract as Low-Cost, Eco-Friendly Inhibitors of Corrosion on Mild Steel in an Acidic Media, American-Eurasian Journal of Scientific Research, 2016: 11 (3), 177-182.
8. ACHARYA, M., Green Inhibitors for Prevention of Metal and Alloys Corrosion: An Overview, Chemistry and Materials Research, 2013: 3 (6).

9. Alaneme, K.K., Olusegun,S.J., Corrosion inhibition performance of lignin extract of sun flower (Tithoniadiversifolia) on medium carbon low alloy steel immersed in $\mathrm{H}_{2} \mathrm{SO}_{4}$ solution, Leonardo J. Sci. , 2012: 20 (11), 59-70.

10. Olusegun,S.J.,Adeiza,B.A., Ikeke, K.I., Bodunrin,M.O., JatrophaCurcas leaves extract as corrosion inhibitor for mild steel in $1 \mathrm{M}$ hydrochloric acid, J. Emerging Trends Eng. Appl.Sci. , 2013, 4 (1):138-143.

11. Alaneme,K.K. Daramola,Y.S., Olusegun, S.J., Afolabi,A.S., Corrosion inhibition and adsorption characteristics of Rice husk extracts on mild steel immersed in $1 \mathrm{M} \mathrm{H}_{2} \mathrm{SO}_{4}$ and $\mathrm{HCl}$ solutions, Int. J. Electrochem. Sci., 2015: 10, 3553-3567.

12. L.Y.S. Helen, A.A. Rahim, B. Saad, M.I. Saleh, P. Bothi Raja, Aquilariacrassna leaves extracts - a green corrosion inhibitor for mild steel in $1 \mathrm{M} \mathrm{HCl}$ medium, Int. J. Electrochem. Sci., 2014: 9, 830-846.

13. Ashassi-Sorkhabi, H., Seifzadeh, D., The inhibition of steel corrosion in hydrochloric acid solution by juice of Prunuscerasus, Int J. Electrochem. Sci., 2006:1, 92-98.

14. Singh, A.,Ahamad,I., Yadav,D.K., Singh, V.K., Quraishi,M.A., The effect of environmentally benign fruit extract of shahjan (Moringaoleifera) on the corrosion of mild steel in hydrochloric acid solution, Chem. Eng. Commun. 2012 : 199 (1), 63-77. 
15. K.S. Beenakumari, Inhibitory effects of Murrayakoenigii (curry leaf) leaf extract on the corrosion of mild steel in $1 \mathrm{M} \mathrm{HCl}$, Green Chem. Lett. Rev., 2011: 4 (2), 117-120.

16. Abiola, O.K. James,A.O., The effects of Aloe vera extract on corrosion and kinetics of corrosion process of zinc in $\mathrm{HCl}$ solution, Corros. Sci., 2010: 52 (2), 661-664.

17. Mehdipour,M.,Ramezanzadeh,B.,Arman,S .Y., Electrochemical noise investigation of Aloe plant extract as green inhibitor on the corrosion of stainless steel in $1 \mathrm{M} \mathrm{H}_{2} \mathrm{SO}_{4}, \mathrm{~J}$. Ind. Eng. Chem.,2015: 21, 318-327.

18. Ji,G.,Anjum, S.,Sundaram,S., Prakash,R., Musa paradisica peel extract as green corrosion inhibitor for mild steel in $\mathrm{HCl}$ solution, Corros. Sci., 2015: 90, 107-117.

19. Mourya,P., Banerjee,S., Singh,M.M., Corrosion inhibition of mild steel in acidic solution by Tageteserecta (Marigold flower) extract as a green inhibitor, Corros. Sci.,2014: 85, 352-363.

20. Sivakumar, P. R., and Srikanth, A. P., Inhibitive action of aqueous extract of Holopteleaintegrifolia leaves for the corrosion of mild steel in $1 \mathrm{~N} \mathrm{HCl}$ solution, Der PharmaChemica, 2016: 8(19), 433-440.

21. Vishalakshi,K.,Sivakumar, P.R., and Srikanth,A. P., Analysis of Corrosion Resistance Behavior of Green Inhibitors on Mild Steel in $1 \mathrm{~N} \mathrm{HCl}$ Medium Using Electrochemical Techniques, Der PharmaChemica,2016: 8(19), 548-553.

22. Olufunmilayo E. Adejumo, Adelodun L. Kolapo1, Akintomiwa O. Folarin, Moringaoleifera Lam. (Moringaceae) grown in Nigeria: In vitro antisickling activity on deoxygenated erythrocyte cells, Journal of Pharmacy and Bioallied Sciences, 2012: 4(2), 17-30.
23. Omotoso,O. D.,Adelakun,S. A., Amedu1, N O., and Idoko,U. P., Antioxidant Properties of Moringaoleifera Oil and Anacardiumoccidentale Oil on Cadmium Induced Liver Damage in Adult Wistar Rats, Journal of Advances in Medical and Pharmaceutical Sciences,2016: 7(4): 1-7.

24. Rowland Monday Ojo KAYODE, Anthony Jide AFOLAYAN, Cytotoxicity and effect of extraction methods on the chemical composition of essential oils of Moringaoleifera seeds, Journal of Zhejiang UniversitySCIENCE B (Biomedicine \& Biotechnology), 2015: 16(8), 680-689.

25. AnupamaPriadarshini, PranayPunjPankaj, M C Varma and K Kumar, Evaluation of the antibacterial potential of Moringaoleifera and Azadirachtaindica against some pathogenic microbes: A comparative study, International Journal of Drug Development \&Research January-March, 2013: 5 (1), ISSN 09759344.

26. PoornimaShukla and ManojTripathi, Pharmacognostical Evaluation and Antimicrobial activity of MoringaoleiferaLamk. Leaf, Int. J. Pure App. Biosci., 2015: 3 (5), 95100.

27. Farooq Anwar, SajidLatif, Muhammad Ashraf and Anwarul Hassan Gilani, Moringaoleifera : A Food Plant with Multiple Medicinal Uses, Phytotherapy Research, 2007: 21, 17- 25.

28. K; Mansouri, L; Sekhri,O; Rahim, and A; Tabchouche.A Comparative electrochemical study on corrosion inhibition of iron by synthesized tetraphenylphosphonuim iodide in acid media.Orient. J. Chem., 2016.,32(4), 2015-2025. 